\title{
Self-Compassion and Self-Protection in Two- Chair Technique: Consensual Qualitative Analysis of Transcribed Video-Recordings
}

\author{
Viktória Vráblováa, Júlia Halamová ${ }^{\mathrm{b}}$, Bronislava Strnádelovác, \\ Slávka Zlúkyová ${ }^{d}$, Alžbeta Dvoranová
}

[a] Institute of Applied Psychology, Faculty of Social and Economic Sciences, Comenius University in Bratislava, Slovakia.

[b] Institute of Applied Psychology, Faculty of Social and Economic Sciences, Comenius University in Bratislava, Slovakia.

[c] Institute of Applied Psychology, Faculty of Social and Economic Sciences, Comenius University in Bratislava, Slovakia.

[d] Institute of Applied Psychology, Faculty of Social and Economic Sciences, Comenius University in Bratislava, Slovakia.

[e] Institute of Applied Psychology, Faculty of Social and Economic Sciences, Comenius University in Bratislava, Slovakia.

\section{Abstract}

Even though self-compassion and self-protection are associated with well-being and mental and physical health, qualitative research in this area is very rare. As no study has compared selfcompassionate and self-protective responses during the two-chair technique, the aim was to analyze participants' subjective responses in reacting to self-criticism during the technique and compare self-compassionate and self-protective statements. The research sample comprised 80 participants; 60 women and 20 men $(M=23.86$; $S D=5.98)$. The investigation underwent consensual qualitative analysis. The results showed four main domains for self-compassion and self-protection: cognitive, behavioral, emotional, and interpersonal aspects. In several cases, the participants utilized self-compassion and self-protection simultaneously or subsequently, and both types of responses to some degree supplemented each other or were intertwined. Self-protection and self-compassion are complimentary. Only by combining these two constructs can individuals assertively protect themselves while being kind to themselves and others. In the case of selfcompassion, the results confirm several findings from previous studies, but in the case of self- 
protection, this is the first more detailed exploration of this construct because it has not been studied sufficiently to date.

Keywords: self-protection; self-compassion; self-criticism; consensual qualitative research; twochair technique.

\section{Table of Contents}

Two-chair technique

Qualitative research of self-compassion and self-protection

The aim of the research study

Methods

Results

Discussion

Limitations

Conclusion

References

Psychological Thought, 2021, Vol. 14(2), 378-401, https://doi.org/10.37708/psyct.v14i2.573

Received: 2021-01-04. Accepted: 2021-04-02. Published (VoR): 2021-10-31.

Handling Editor: Natasha Angelova, South-West University "Neofit Rilski", Blagoevgrad, Bulgaria.

${ }^{*}$ Corresponding author at: Institute of Applied Psychology, Faculty of Social and Economic Sciences, Comenius University in Bratislava, Slovakia. E-mail: julia.halamova@gmail.com

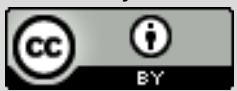

This is an open access article distributed under the terms of the Creative Common Attribution License (https://creativecommons.org/licenses/by/4.0), which permits unrestricted use, distribution, and reproduction in any medium, provided the original work is properly cited.

According to its author Greenberg (2017), the main goal of Emotion-Focused Therapy (EFT) is to help clients recognize their own emotions and know how to use them effectively. This psychotherapeutic approach supports the recognition, acceptance, utilization, expression, regulation, and transformation of emotions. The therapy aims to focus on awareness, motivation, interaction, behavior, strengthening of the self, and influence regulation. Moreover, its objective is also to create a new meaning while emphasizing emotions, establishing the primary path to change. In this therapy, clients face emotions that they fear and, thus, they become aware of what particular emotions mean and why they are important in a given situation, thereby learning to recognize their desires and needs (Greenberg, 2017).

Neff (2012) presented self-compassion as kindly treating oneself, even in situations of one's own suffering and failure, while Gilbert (2010), on the other hand, considered self-compassion as a motivation to be caring towards oneself in unpleasant life situations. On the other hand, selfprotection helps the client fight for their unmet needs and rights, empowers them to set limits, and 
be assertive against evil in the subsequent steps toward fulfilment of their needs. (Timulak \& Pascual-Leone, 2014). EFT utilizes self-compassion and self-protective anger as the main adaptive strategies (Halamová, 2015), facilitating therapeutic change. The Emotion-Focused Training for Self-Compassion and Self-Protection (EFT-SCP) (Halamová et al., 2018b) utilizes selfcompassion and protective anger simultaneously because they have proven to be effective tools in contributing to decreasing self-criticism and increasing self-compassion. Self-compassion acts as a remedy for self-criticism, while not actually suppressing the self-critical process itself but integrating emotional pain, which contains unsolved or self-critical experiences, thereby helping the client access self-supportive alternative internal resources (Sutherland et al., 2014). Protective anger is particularly important, because it decreases submissiveness in people with a low level of selfcompassion (Akin, 2009) and self-image (Pascual-Leone \& Greenberg, 2007), making it easier for them to stand up against their self-critic (Halamová, 2018).

\section{Two-chair technique}

The therapeutic use of the two-chair technique is supposed to encourage clients to access, express, and process suppressed emotions and aspects of the self (Greenberg, 2002). According to Greenberg (1979), the two-chair technique represents two sides of the split personality. A dialogue takes place between the two sides (Greenberg et al., 1993). The goal is for the two sides to communicate with each other (express attitudes, thoughts, feelings, needs, etc.), to get to know each other, and integrate. According to Shahar et al. (2012), the two-chair technique effectively decreases self-criticism, anxiety, and depression symptoms while significantly increasing selfcompassion and self-reassuring.

\section{Qualitative research of self-compassion and self-protection}

Qualitative research of self-compassion often concentrates on the effects of training focused on its development (Binder et al., 2019), for instance, self-compassion role in attaining athletic potential (Ferguson et al., 2014) in connection with emotional pain and self-compassion in female athletes (Sutherland et al., 2014), the importance of self-compassion for women dealing with post-partum changes (Woekel \& Ebbeck, 2013), or for example, studying cancer patients' partners and their experiences with online intervention based on self-compassion (Köhle et al., 2017). Some training focuses on self-protection as well. For example, Koróniová et al. (2020) research results showed positive effects of EFT-SCP, since following the training their highly self-critical participants reacted with more adaptive emotions and models than prior to the training.

The self-compassion construct itself, was studied by Bayir and Lomas (2016). They analyzed indepth semi-structured interviews about self-compassion of people who exhibited a problem with 
self-compassion. The authors found the following four major themes: self-compassion deficiencies, perfectionism - a double edge sword, the third-person effect, and self-criticism benefits. Similarly, Campion and Glover (2016) conducted interviews as a part of an intervention program and found three dominant themes: being self-compassionate, self-compassion benefits, and selfcompassion obstruction. The participants perceived self-compassion as beneficial, but they also thought others would judge them and that self-compassion leads to vulnerability (Campion \& Glover, 2016). Furthermore, Halamová et al. (2018) studied the first free associations of compassion and self-compassion and found the following four main domains: cognitive, emotional, behavioral, and judgmental aspects of compassion/self-compassion. Their participants perceived self-compassion mainly from the point of positive emotions such as love and tranquility and negative emotions such as sadness, regrets, and unhappiness through cognitive understanding and behavioral expressions of self-aid by means of self-confidence and self-support. Halamová et al. (2019) studied self-compassion in the framework of internal self-compassionate imagination on the part of the participants, which the authors also compared in terms of their self-criticism level. They found differences between high and low self-critical individuals, not only on selfcompassionate but also on self-critical and self-protective imaginations. Low self-critical individuals manifested better ability to cope with their own self-criticism compared to high self-critical individuals. Despite this, the low self-critical individuals had to remind themselves what the selfcompassionate and self-protective part of them needs to do to overcome self-criticism. Although several qualitative studies deal with self-compassion, some deal with self-protection, but none focus on comparing the two constructs.

\section{The aim of the research study}

To date, no other study has analyzed and compared self-compassionate and self-protective responses during the two-chair technique. That is why this study aimed to analyze the participants' subjective responses while reacting to self-criticism during the two-chair technique, and to compare self-compassionate and self-protective statements. 


\section{Research procedure}

\section{Methods}

The work in this study is based on research done by Whelton and Greenberg (2005) and Kramer and Pascual-Leone (2016). In this study, the two-chair technique was utilized during which the participants first spent 5 minutes criticizing themselves and subsequently spent 5 minutes reacting to this self-criticism. The discussion was video recorded.

To start, the participants were welcomed, were given brief information about the study and were asked for an online consent to the research. The laboratory room had two chairs facing each other, 0.6 meters apart. Two cameras were placed on a tripod, each 1.5 meters from the chair, videoing the opposite chair. The video was taking the sitting participant from the waste up.

After the part where the participant self-criticizes, they received the following instruction to react to the self-critic: "Please take a seat on the opposite chair. Now you are on your own. Where you were sitting before for five minutes you were on the receiving end of criticism. Your role now is to confront this criticism. How does it feel to be criticized like that? How will you react to it? How will you respond to your inner self-critical voice and to the criticism you have received from this critical voice? You have again approximately 5 minutes to respond. Please use second person singular. Speak for 5 minutes from this position and I will let you know when your 5 minutes are up." If the participant got stuck, the research assistant would offer encouragement in the form of additional questions, such as: "What do you usually say to yourself after you have criticized yourself? And what else? Anything else? This was followed by short debriefing and thanks for cooperation.

\section{Research sample}

The research sample was selected randomly using the snowball method, which was done through social networks, posters, and university emails. The sample comprised 80 participants (60 women, 20 men), aged 19 to 57 years $(M=23.86$; $S D=5.98)$. Of the total number of self-compassionate responses, the most expressive ones were selected and responses were gradually added until the categorization was saturated. Since there were substantially fewer self-protective responses and they occurred in a smaller number of participants, all of them were analyzed. The research sample for self-compassion consisted of 20 participants (16 women and 4 men) aged 19 to 32 years ( $M=$ 22.09; $S D=3.29$ ) and for self-protection 58 participants (58 women, 13 men) aged 19 to 57 ( $M=$ 24.26; $S D=6.67$ ).

\section{Research team}

The team consisted of 5 researchers - 3 Master's Degree psychology students and 2 auditors, academic researchers (professors, $\mathrm{PhD}$ ). The researchers wrote out their expectations prior to 
beginning of the research in order to prevent subjective distortions during coding and data analysis.

\section{Data analysis. Consensual qualitative research}

Data were analyzed using consensual qualitative analysis (CQR; Hill et al., 1997). The CQR data are collected based on open questions; the analysis uses words instead of numbers and examines a small number of cases. The case context is important in order to understand the individual parts. A consensus among the researchers preceded any conclusions reached (Hill et al., 1997).

In accordance with recommendations by Hill et al. (1997), the procedure was as follows: The first step involved transcribing the video recordings of the participants' responses. As the next step, the researchers individually coded the transcribed monologues, creating domains, subdomains, and categories. After completing this process, the researchers discussed and agreed on the categorization. The coded data were subsequently discussed with the auditors, who offered feedback and suggestions for the finalization. The self-compassion coding took place in two phases. In the first phase, 16 transcriptions of expressive participants were analyzed, and in the second one, 4 more transcriptions were added to the coded data, and the categorization saturation was verified. The self-protection coding differed from the self-compassion because self-protection responses occurred less often and were less detailed and, therefore, it was decided to code the whole sample after excluding participants whose responses did not reflect any self-protection.

\section{Results}

Regarding the self-compassion and self-protection constructs, the data revealed the following four main domains: cognitive aspects, behavioral aspects, emotional aspects, and interpersonal aspects (see Table 1). Cognitive aspects correspond to mental representations, reflections, and rational thoughts on the part of the participants. Behavioral aspects note the participants' behavioral tendencies, moving from the past through the present up to the future. Emotional aspects comprise all participants' expressed feelings and emotions communicated directly (verbally) or indirectly (paraverbally). Interpersonal aspects offer a view of the other people or their perceptions, mutual interaction, or comparing oneself to others.

Overall, for self-compassion were coded 204 verbal statements and paraverbal expressions, which were categorized into 4 domains, 7 subdomains, 12 categories, and 40 subcategories. For selfprotection, were coded 112 statements and categorized the same number of domains (4) and subdomains (7), but 18 categories and 6 subcategories. 
Table 1.

Consensual analysis of cognitive and behavioral aspects of self-compassion and self-protection responses.

\begin{tabular}{|c|c|}
\hline \multicolumn{2}{|c|}{ Cognitive aspect } \\
\hline Cognitive aspects of self-compassion (86) & Cognitive aspects of self-protection (30) \\
\hline Self-compassion argumentation (22) & Self-protective argumentation (30) \\
\hline Understating a situation (10) & You have the right to evaluate limits (14) \\
\hline It doesn't matter (6) & You have the right to say no (3) \\
\hline It's not so bad (4) & You have the right to decide situationally (7) \\
\hline Everything has its reasons (3) & You have the right to consider the importance (4) \\
\hline Learning a lesson (12) & You have the right to look for a meaning (11) \\
\hline You can avoid a mistake (4) & You have the right to decide what is normal (5) \\
\hline \multicolumn{2}{|l|}{ Correct a mistake (1) } \\
\hline \multicolumn{2}{|l|}{ Undo a mistake (1) } \\
\hline \multicolumn{2}{|l|}{ Learn from a mistake (6) } \\
\hline \multicolumn{2}{|l|}{ Realizing one's own worth (43) } \\
\hline \multicolumn{2}{|l|}{ Be yourself (6) } \\
\hline \multicolumn{2}{|l|}{ You're unique (5) } \\
\hline \multicolumn{2}{|l|}{ Remember your positive traits (32) } \\
\hline \multicolumn{2}{|l|}{ You're capable (6) } \\
\hline \multicolumn{2}{|l|}{ You're intelligent (1) } \\
\hline \multicolumn{2}{|l|}{ You're focused (4) } \\
\hline \multicolumn{2}{|l|}{ You're good (6) } \\
\hline \multicolumn{2}{|l|}{ You're creative (2) } \\
\hline \multicolumn{2}{|l|}{ You're helpful (5) } \\
\hline \multicolumn{2}{|l|}{ You're empathic (1) } \\
\hline \multicolumn{2}{|l|}{ You're witty (3) } \\
\hline \multicolumn{2}{|l|}{ You're just (1) } \\
\hline \multicolumn{2}{|l|}{ You're courageous (3) } \\
\hline \multicolumn{2}{|l|}{ Recognizing failure (21) } \\
\hline \multicolumn{2}{|l|}{ Universality of failure (8) } \\
\hline \multicolumn{2}{|c|}{ You're allowed to fail because everyone fails sometimes (7) } \\
\hline \multicolumn{2}{|c|}{ First you're up, then you're down (1) } \\
\hline \multicolumn{2}{|l|}{ You're allowed to be imperfect (13) } \\
\hline & \\
\hline Behavioral aspects of self-compassion (49) & Behavioral aspects of self-protection (26) \\
\hline Motivation for behavior (42) & Right to behave (13) \\
\hline View into the future (21) & You have the right to set your limits (6) \\
\hline It will get better (12) & You have the right to do things as best as you can (6 \\
\hline You have enough time (4) & You have the right to do things the way you want to (7) \\
\hline You will get ahead (4) & You have the right to postpone things (4) \\
\hline You need to develop skills (1) & \\
\hline You have the right to do more important th & \\
\hline Encouragement (20) & \\
\hline Don't give up! (3) & \\
\hline You can do it (8) & \\
\hline You will reach your goal (5) & \\
\hline Keep trying (4) & \\
\hline Behavioral caring for oneself (7) & Standing up for oneself (13) \\
\hline Soothing yourself (7) & Stand up to your inner critic (6) \\
\hline You can't change that (3) & Defend yourself (7) \\
\hline Do something for yourself (2) & \\
\hline Don't worry (2) & \\
\hline
\end{tabular}




\section{Cognitive aspects (self-compassion)}

The subdomain "Self-compassionate argumentation" reflects the rational way participants are thinking and perceiving demanding life situations or failures. It comprises two categories and their subcategories. The "Understating a situation" includes responses associated with recreating perceptions of a difficult situation or a situation of failure and trying to understand, justify and alleviate failure: "It doesn't matter" (“...if it's not a matter of life and death then it doesn't matter ... and it's not worth all the stress ..."), "It's not so bad" ("So ... so it's not so totally ... bad as you sometimes think ..."), "Everything has its reasons" ("... well, simply take things as they are; that sometimes things don't go our way, or didn't go our way for some reason."). The category "Learning a lesson" contains instructions for the future, which should increase the chance for success: "You can avoid a mistake" (“... somehow figure out what you were doing wrong and not repeat it."), "You will rectify a mistake" (" so ... so, basically, also that we make mistakes and learn where the mistake was made and then later correct it."), "Undo a mistake"("We should look for the reason and then try to undo it ..."), "Learn from a mistake" (“.. I don't take it as some huge failure of mine, but I take it as a learning lesson ...").

The subdomain "Realizing one's own worth" reflects emphasizing the perception of the self. It consists of 3 categories: "Be yourself" ("And you take a deep breath ... , like finally, I am so happy that I am here and I am me ... myself"), "You are unique" ("Your ability is unique even if you sometimes feel like maybe ... you're just average, or just a little grey mouse, but that's not true, because ... you have many traits that other don't have"). The last category "Remember your positive qualities" consists of 10 subcategories: "You are capable" (You are capable, you work hard, which is reflected in the results."), "You are intelligent" (" ... you are intelligent, hmm ..."), "You are focused" ("So, hmm ... you are also focused and you can ... you can get what you need."), "You are good" ("... and maybe ... a good person, basically I am not bad."), "You are helpful" ("In spite of you bad qualities and abilities you still know how to ... help others in each situation."), "You are empathic" ("You are very kind and ... hmm ... maybe those are also your positive qualities that you're ... hmm ... very nice, and so empathic like other people, maybe ... maybe even a little more ..."), "You are witty" (Well ... , that I am witty ..."), You're just" (“... you're just and in the end you always say it ... the truth ... and everything the way it is supposed to be."), "You're courageous" ("You're brave ...").

The subdomain "Recognizing failure" deals with failures and set-backs and we are defining it using two categories. First category "Universality of failure" talks about general human experience with failure with the following subcategories: "You're allowed to fail because everyone fails sometimes" 
("It is human to fail sometimes."), "First you're up, then you're down" ("Simply put, we have periods when you're happy, joyful and you're doing really well, and not just you but most people, that it is a state and that's the way it is with people, first you're up, then you're down; that's just the way it is."). The category: "You're allowed to be imperfect" points to, in a kind and accepting way, individual imperfections, of which our participants were well aware ("So ... it's sometimes difficult to realize all the bad things you think you're are or have but every coin has two sides, and so do you, and when you concentrate on the good side ... you can move forward ...").

\section{Cognitive aspects (self-protection)}

The main theme of the self-protective responses, within the cognitive aspects, was the rational defense of the right to decide on your own. In particular, our participants evaluated their own limits: "You have the right to say no" (“... I simply knew one thing for sure, what I don't want to do..."), "You have the right to decide situationally" (“... certainly, there were situations or circumstances, which led me to behave the way I did ..."), "You have the right to consider the importance" (“... that time in the summer, I simply, I just had more important things to deal with and I just forgot"). In the category "You have the right to look for a meaning" the participants argued using subjective perception of the rational explanation for the reason of their actions ("I know I shouldn't have been drinking, but I needed a drink to relax among all these people I didn't know ..."). The last category "You have the right to decide what is normal" shows the importance of judging yourself and your actions in the context of normality (“... well sometimes I just don't feel like it and that's completely normal. It's simply totally $\mathrm{OK}$, because ... because it's just normal.").

\section{Behavioral aspects (self-compassion)}

The subdomain "Motivation for behavior" includes responses, which the participants use to activate and encourage themselves in a time of failure, which leads them to subsequent future behavior. The category "View into the future" deals with future behavior and moving forward, whereby participants invoke their own time constraints which they use to motivate them. The responses were divided into the following subcategories: "It will get better" ("Hmm ... and the future ... it will only get better, it will improve."). "You have enough time." ("Look, you're still in the first half of your life, how many more years you have ahead. If medicine continues like this, you'll live to a hundred and you'll be sad because you won't know what to do with your time. So, don't stress out."), "You will get ahead" ("And ... these failures too move you ahead, so that you become better than you are, that you move forward by the character of your personality."), and "You need to build skills" ("Yes, that was the first time, but that happens to everybody, the cake you bake the first time is not 
always good. Not even my mom was such a great baker at first. Even she had to build some skills."). In the category "Encouragement" we placed responses of participants who encouraged themselves look for future accomplishments following a failure. They stressed the idea of not giving up: "Don't give up!" "Don't give up. This happened many times, and it will happen again, so just go on."), "You can do it" ("So you will certainly be able to do it. You've managed to cope with worse situations than this one."), "You will reach your goal" ("You will succeed, and everything will be good. So far, everything has ended OK, so you'll be able to do it."), "Keep trying" ("Try, try what you can do. Something will work and maybe ... maybe it will work perfectly, maybe ... maybe ... hmm, you're afraid to be lucky).

The subdomain „Behavioral caring for oneself“ captures active tendencies to take care of the self behavioral help offered to oneself, and diminish negative experiencing in the framework of one category with the following 3 subcategories: The category "Soothing oneself" contains dealing with a difficult situation by soothing oneself: "You can't change that" ("And this always calms me down, that ... you can't change that, so let's go on."), "Do something for yourself" ("Find your strong side or the positive side and use that to accomplish something. Just sort of ... remember it and keep, keep these sides in mind not the bad ones, ... and ... this will help you. Anyway, that will help you ..."), ("Don't worry" (“... anyway ... we will keep working, so ... so to worry about it for weeks and so ... that's not good.").

\section{Behavioral aspects (self-protection)}

The subdomains in self-protection branched out to "The right to behave" and "Standing up for oneself". In the first subdomain, the participants justified their behavior within their own limits and two categories arose: "You have the right to set your limits" with the subcategory of "You have the right to do the best you can" ("You don't have to do things perfectly. Just, that the way I did it is the best way I knew how.") and, in our case, the second category "You have the right to do things the way you want to" contains 2 subcategories: "You have the right to do more important things" ("... that I have my own life and sometimes I can't be with them.") and "You have the right to postpone things" (“... that, I can take a break for a minute ... that, its' not going to kill me when, for example, I watch my show or read something else or just browse the internet. That's not going to kill anyone."). In the second subdomain the participants stand up for themselves against their inner critic ("It is not totally OK to criticize like that ...") and they defend/fight for their behavior in the context of a critic and in the context of other people ("Be strong, don't let them humiliate or defeat you."). 
Table 2.

Consensual analysis of emotional and interpersonal aspects of self-compassion and selfprotection responses.

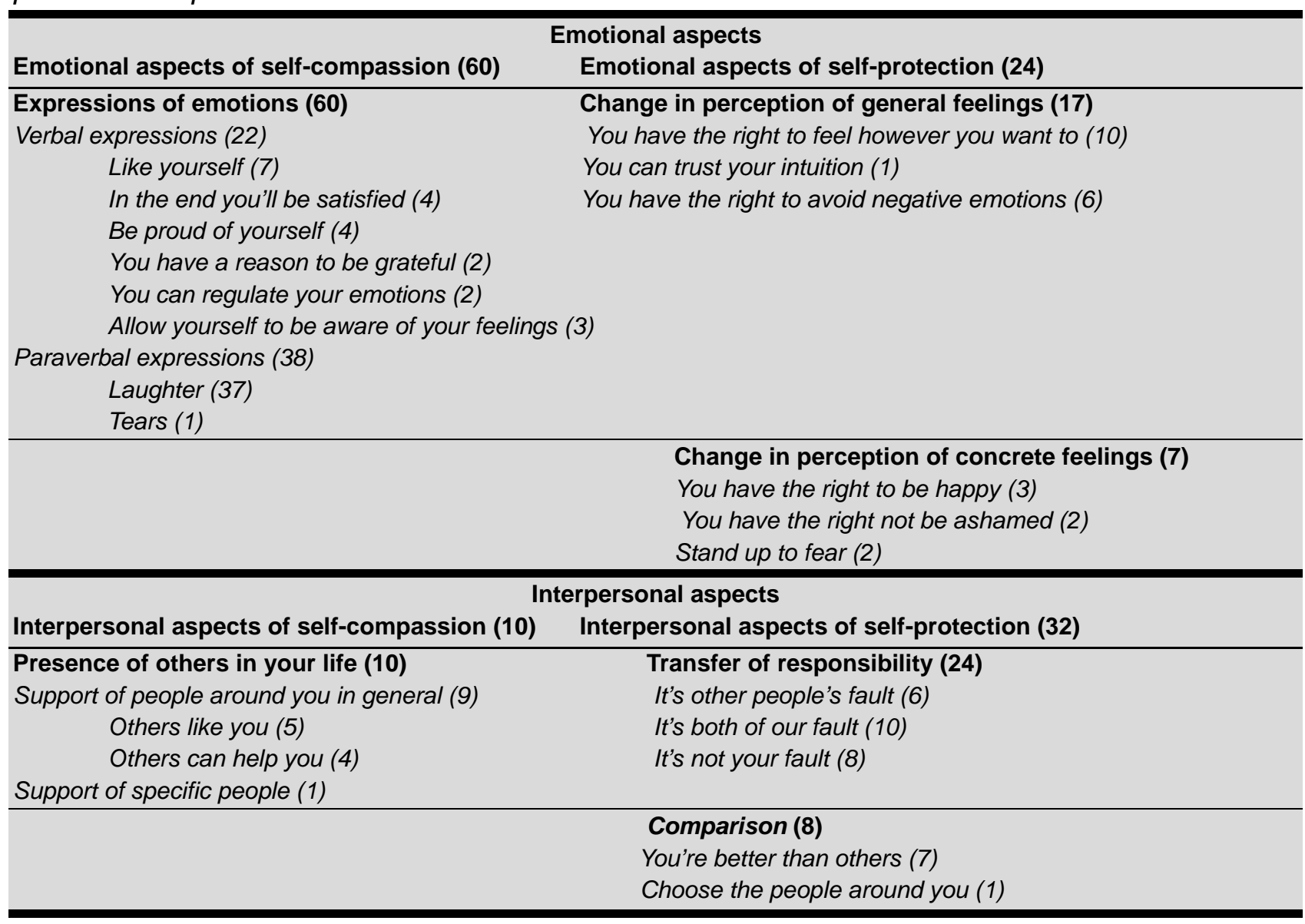

\section{Emotional aspects (self-compassion)}

The subdomain "Expressions of emotions" captures the way emotions were expressed. The first category, "Verbal expressions" involves the participants' verbal communication used to express or describe emotions. We divided the statements into 6 subcategories: "Like yourself" ("Every human being is pretty, you are pretty too. So, like yourself"), "In the end you will be happy" (Eventually the moment will come when you will breathe easy and say to yourself that you're happy with where you are, and I believe that that will happen one day. Either with someone, or you by yourself or somewhere in another country or at home in Slovakia, anywhere."), "Be proud of yourself" ("... you can be proud, you can help people the way you have so far and... and ... it will be amazing."), "You have a reason to be grateful" "You know that you have people, you have great people around, you have great people around you for which you can only be grateful"), "You can regulate your emotions" (I feel the best when I know that I have reached certain stability and that ... I don't deny that I failed, that it's OK when I can admit to that and go forward."), "Allow yourself to be aware of 
your feelings" ("You know, I think I need to hear that ... maybe even that ... sort of ... analyze it ... these feelings, what does it all mean."). In the second category "Paraverbal expressions" were reported direct expressions of emotions, such as "Laughter" - were included chuckle and laughter. "Tears" - crying happened only once in a form of a release of internal experience.

\section{Emotional aspects (self-protection)}

The change in feelings perception offered comfort to the participants, be it a change in general or particular feelings, and as a result they demanded the right to feel whichever way they wanted or needed ("Hmm ... I guess sometimes I need to hear that ... yes, you have the right to feel like that, that yes, it isn't all bad, but even if it is, you still have the right because you simply do, and maybe I'd like to hear that it's OK ... that's the way it is, even if it is like that, it is OK."), to some participants what mattered was avoiding negative feelings ("That I can't let it happen ... that I should feel like this because of some person, when they're not even my family or anybody close to me."), and in one case a participant focused on his trust in his own intuition (" ... if I didn't go there because I felt anxious then that means that that feeling of anxiousness was justified ..."). As regards particular emotions, participants labeled happiness ("I was happy, I slept well, and I wasn't constantly thinking about what someone will say. It's a matter of my own happiness and how I will feel in this life. The deal is that I have to be happy with the way I am living my life."), shame ("... so I don't even have to feel ashamed, or feel bad ..."), and fear ("And maybe be a bit braver and face my fear.")

\section{Interpersonal aspects (self-compassion)}

The subdomain "Presence of others in your life" points to the interaction with other people, involving kind caring and support from others divided into two categories: "Support of people around you in general" - this category demonstrates a general form of support. Participants realize that others like them and that they are not alone. This category was divided into two subcategories: "Other people like you" ("... you have people around you, who like you and they don't see you at all in a negative way; you just have to realize this."), "Other people can help you" ("You know that you can rely on them and they will help you whether it's 3 AM or 3 ... 3 PM, they will be there for you, so you have to think about the fact that you're not alone and you need to really give thanks"). In the category "Support of specific people" (“... you have an amazing advisor, who helps you a lot ... You are not alone.") one participants noted a specific person and that is why we decided to create a separate category. 


\section{Interpersonal aspects (self-protection)}

The subdomains in the interpersonal aspects branched out to: "Transferring responsibility" and "Comparison". The first three categories involve transferring of blame: "It's the other people's fault" (But it's not your fault, I am telling you ... and your psychologist told you too and now I am telling you again, that it wasn't your fault but only his, that he did it. It is not your fault, you didn't want to split the family and you don't know how it would turn out in the end, anyway."), "It's both of our fault" ("It's the fault of the other person too."), "It's not your fault" ("Even if no one admits to it, you don't have to admit to it, if it's not your fault."). In the second part of the categorization, one can see a comparison with the others: "You're better than the others" (You're tenacious, because many people would have given up long time ago. And you have said that others wouldn't have been able to handle it."), "Choose the people around you" (Surround yourself only by those people, who bring something positive to your life. People who bring a lot of negative stuff, you should filter them out and don't waste time with them ...").

\section{Discussion}

The aim of the research was to analyze participants' subjective responses while they were reacting to self-criticism during the two-chair technique and examine the specifics.

\section{Cognitive aspects}

Alleviating suffering as part of compassion and self-compassion is incorporated in theory by Strauss et al. (2016). This is similar to the responses of this study's participants, who use cognitive argumentation to alleviate their own suffering. Learning a lesson can also be taken as another cognitive and kind approach to failure because the participants are not punishing or judging themselves. They interpret the situation as an opportunity for a change for the better. They learn something positive from failure. Thus, they focus primarily on learning from their own mistakes, not repeating the same mistakes in the future, and rectifying them. Self-compassion, in this case, is characterized by a balanced approach in demanding situations (Neff, et al., 2007a). In the categories described above, we also noted awareness (Neff, 2003a), characterized by an objective view of one's own failure, i.e., not denying or suppressing experiencing but rather accepting thoughts and feelings just the way they are (Halamová \& Kanovský, 2018). In the subdomain "Realizing one's own worth" the participants emphasize the importance of being themselves and point to their own uniqueness. According to Neff (2003b), paradoxically a constructive and healthy attitude toward the self comes from strengthening and building a unique and independent identity. 
Some participants reminded themselves of and emphasized their positive characteristics. This could be interpreted as a form of self-support because, according to Berking and Whitley (2014), in self-compassion, there is a creation of distance between "observing self" and "suffering self" through sufficient empathy towards oneself. In addition, self-compassion in the framework of mental health is positively associated with personality characteristics such as curiosity, wisdom, optimism, amiability, extroversion, or conscientiousness (Neff, et al., 2007b), which may point to the interconnection between personality and self-compassion. The characteristics associated with performance could be interpreted regarding self-confidence because Neff (2003b; Neff \& Vonk, 2009) considers self-compassion to be a good alternative to self-confidence. Positive characteristics in the domain of relationships (e.g. "You are helpful") suggest prosociality since it correlates positively with self-compassion (Marshall et al., 2020). The subdomain "Recognizing failure" along with the category "Universality of failure" is tied to another self-compassion component described by Neff (2003b), and that is general human experience with the subcategories of "You're allowed to fail because everyone sometimes fails" and "First you're up, then you're down". At the same time, participants felt like they didn't have to compare themselves with others because in the category "You are allowed to be imperfect," they realized that it is OK to be imperfect.

Similar to Larrick's (1993) depiction of self-protective people, the participants of this study tended to justify their behavior in various ways and argue on their own behalf, which means decide for themselves. The category "You have the right to set your limits" underscores the right to say no, situational decision-making, and subjective importance. The use of self-protection is influenced to a great degree by situational factors as well (Cali et al., 2013). The category "You have the right to decide situationally" corresponds to the self-handicap category (Čopková, 2019). In this research, the participants perceived these strategies as unavoidable and of great value. It could be assumed that the participants focused on external factors, which they perceived as causing the failure or could not have been prevented due to a situational context. In the category "You have the right to consider the importance," the participants preferred personal matters, which could be interpreted as determining the individual's subjective priorities. Priorities can, in general, help people make decisions, which would make it a preferential choice (Goldstein \& Hogarth, 1997). It is even probable that defending one's own behavior takes place based on retrospection - the participants defended the sequentiality of their actions. Furthermore, the participants point to the unchanging part of their life in the category "You have the right to say no", where they defend their actions based on a certain setting determining the direction in which they should go. Another bias, which we have noticed in the case of cognitive aspects, is self-licensing, which is found in the categories 
"You have the right to look for a meaning" and "You have the right to decide what is normal" (Čopková, 2019).

As far as cognitive aspects are concerned, there are differences in the overall number of coded responses. In terms of self-compassion, there could be noted empathic alleviation of a situation, recognition of the universality of failure, and the possibility of learning from it, along with remembering one's own worth. In terms of self-protection, the participants perceived as important to underscore their own limits and the right to decide what is normal and give experiences their own meaning.

\section{Behavioral aspects}

"Motivation for behavior" in behavioral aspects ("Encouragement", Don't give up!", You will reach your goal", "You can do it", "Try it") is a self-compassion subdomain, which comprises activating and stimulating expressions concerning future behavior. According to Neff and Dahm (2015), selfcompassion motivates one to reach goals using a kind and caring approach to oneself. The subdomain "Behavioral caring for oneself " references direct actions taken to alleviate suffering. In its category, "Soothing oneself" statements refer to compassion with the suffering self and alleviating suffering by the appropriate behavior. This category also includes the subcategory "You can't change that," which we see as accepting one's own failure (Germer, 2009) and tolerating unpleasant feelings (Strauss et al., 2016). There was also an empathic component of selfcompassion (Berking \& Whitley, 2014; Strauss et al., 2016) in the subcategory "Don't worry".

In the self-protection categories, unlike the self-compassion ones, participants encourage themselves to fight more and be assertive in terms of setting limits, applying their own decisions and actions and standing up for themselves. Alicke and Sedikides (2009) also stress the shift in perception in self-protection from current unsatisfying situation to a better future. This explains the tendency to strive for real instead of imagined improvement because as Scheier and Carver (1993) emphasized, if individuals perceive a goal as attainable, they will strive for it even if the process is slow and difficult.

In the categories "You have the right to postpone things" and "You have the right to do more important things" participants realized they have the right to do things according to their own judgment. In the former category, they refer to the ability to postpone things in order to take a rest because optimal balance between rest, work and play is crucial for maximizing health and functions of a human being (Reed \& Sanderson, 1999). That is probably, why participants felt the need for rest in order to function in their everyday lives more effectively. In the category "You have the right to do things as best as you can" several participants realize and accept their mistakes, on 
the one hand, because this realization can move them forward, but on the other hand, they also realize that things don't have to be "perfect". Perfectionism is often associated with self-criticism; thus, the need to eliminate perfectionist thoughts is associated with protection against critical thoughts and failures brought about by the inner critic.

In behavioral aspects, there were differences like the ones in cognitive aspects, because selfcompassionate participants motivated themselves to further action, or to improve and soothe themself, while self-protective participants argued for their rights and standing up for themselves for reasons of protection.

\section{Emotional aspects}

Self-compassionate reaction in the framework of the emotional aspects involved self-love in the subcategories "Like yourself" and "Be proud of yourself". These statements correspond to Neff's (2003b) theory, which describes the self-compassion construct as a kind approach to oneself and one's suffering. Further categories "You can be aware of your feelings" and "You can regulate your emotions" refer to the ability to regulate own feelings, which also follows the theory by Berking and Whitley (2014), who advert to the emotion regulation component in self-compassion. In a similar context, Neff (2003a) discovered existing correlations between emotional intelligence and selfcompassion. The author interpreted this connection from the point of regulation of negative emotions, awareness of one's own experiences and looking at emotions with greater clarity. From the emotional nonverbal expressions, there were included the participants' laughter and tears in the "Paraverbal expressions" category. Unlike laughter, only one participant cried.

In this case, crying was probably an expression of trying to alleviate or relax tension as confirmed by Rydé et al. (2007). It could be seen a similar case in laughing or chuckling. According to Yue et al. (2017), there is a relationship between humour and self-compassion, which in their research is used within coping strategies, emotional regulation, or even overall improvement and strengthening of the self.

During the self-protective monologue, the participants paid little attention to describing specific emotions in the categories "You have the right to be happy", "You have the right not to be ashamed", and "Stand up to fear". They did, however, in a self-protective way, reassured themselves that they have the right to feel whichever way they want and thus can rely on their gut feeling and that they have the right to protect themselves from negative emotions by avoiding them. The self-compassion part of the responses made it possible for the participants to be kind and accepting to themselves and their feelings without giving reasons for the feelings (Neff, 
2003a), but in the framework of self-protection the participants assured themselves in their right to feel anything, trust their gut feelings, be happy and avoid negative emotions.

\section{Interpersonal aspects}

In this framework, the participants elaborated on self-compassionate support from others in the subcategories "Others can help you" and "Others like you" as well as the category of "Support from specific people" within the subdomain of "Presence of others in your life". The participants mainly spoke about support from others in general, but in one case, a participant talked about one specific person. The social interconnection concept points to general humanity as well. Self-compassionate individuals do not feel isolated from others in their failures or in their suffering, and on the contrary, they feel a part of a larger whole - humanity (Halamová \& Kanovský, 2018).

The self-protection categories "It's other people's fault" and "It's not your fault" are again connected with self-handicap (Čopková, 2019). This phenomenon indicates that, among other things evaluating external influences is an important part of self-protection, whereby participants in this study considered these influences unavoidable and, therefore, ascribed their failures to external factors (Sedikides \& Alicke, 2012). Sedikides and Alicke (2012) further note that self-protective people can manifest the "better than average" effect. In this research, there was no explicit comparison with the "average," but there is the potential of this effect to a smaller degree in the categories "You are better than others" and "Choose the people around you".

The self-compassionate portion of the sample searched for support and love of people around them; in the case of self-protection the attitude was about transferring at least part of the blame to others, unlike the case of self-compassion (in cognitive aspects) where self-protective people look for their own worth when comparing themselves to others.

\section{Limitations}

The first limitation is that the participants could have expressed themselves in a socially desirable way because they were being filmed in the presence of two research assistants. In addition, the researchers in the room might not have been totally neutral observers since there might have been certain nonverbal communication between a participant and a researcher. Another limitation of this research is the disproportion of the sample because the vast majority were women and, thus, generalizations may not be valid for a broader population. Further research could concentrate on clinical samples with various diagnoses, whose responses could be compared to the responses of the normal population. Moreover, it would be a contribution to interpret the results knowing the various levels of self-criticism of the participants in order to observe how self-compassionate and self-protective responses differ, in other words, what are the specifics in the two-chair technique. 


\section{Conclusion}

The main contribution of this research study is the overall comparison of self-compassion and selfprotection using the two-chair technique because, to date, no other research has analyzed and compared these individual constructs in this way. In the cognitive aspects of self-compassion, there was empathic understating of a situation, recognizing the universality of failure and the possibility of learning from it, along with being aware of one's own worth. Moreover, in the case of selfprotection, these participants perceived it important to assertively emphasize their own limits and the right to determine what is normal and give their experiences their own meaning. In the case of behavioral aspects, the participants, by being self-compassionate, motivated themselves to further action or to improve and soothe themselves, while participants being self-protective defended their rights, standing up for themselves and their behavior in order to protect themselves. The selfcompassion part of the responses made it possible for the participants to be kind and accepting to themselves and their feelings without giving reasons for the feelings (Neff, 2003a), but in the framework of self-protection, the participants assured themselves in their right to feel anything, trust their gut feeling, be happy, and avoid negative emotions. In self-compassionate responses, the participants searched for support and love from others around them. In terms of self-protection, they tried to transfer at least part of the blame to others, unlike in the case of self-compassion, where self-protective individuals searched for their own worth in comparing themselves to others. Self-protection and self-compassion are complimentary. Only by combining these two constructs can individuals assertively protect themselves while being kind to themselves and others.

\section{Ethical approval}

All procedures performed in studies involving human participants were in accordance with the ethical standards of the institutional and/or national research committee and with the 1964 Helsinki declaration and its later amendments or comparable ethical standards. Ethical committee of Faculty of social and economic sciences Comenius University in Bratislava 8.1.2018 (ref: 3/2018) "Two-chair technique qualitative analysis".

\section{Funding}

Writing this work was supported by the Scientific Grant Agency VEGA under Grant 1/0075/19.

\section{Other Support/Acknowledgement}

The authors have no other support to report.

\section{Competing Interests}

The authors have declared that no competing interests exist. 


\section{References}

Akin, A. (2009). Self-compassion and submissive behavior. Egitim Ve Bilim, 34(152), 138. Retrieved from: https://www.proquest.com/docview/1009842037?accountid=17229\&forcedol=true

Alicke, M. D., \& Sedikides, C. (2009). Self-enhancement and self-protection: What they are and what they do. European Review of Social Psychology, 20(1), 1-48.

https://doi.org/10.1080/10463280802613866

Bayir, A., \& Lomas, T. 2016. Difficulties generating self-compassion: An interpretative phenomenological analysis. The Journal of Happiness \& Well-Being, 4(1), 15-33. Retrieved from: https://repository.uel.ac.uk/item/852y4

Berking, M., \& Whitley, B. (2014). Affect Regulation Training. A Practitioners's Manual. Springer. https://link.springer.com/book/10.1007\%2F978-1-4939-1022-9

Binder, P. E., Dundas, I., Stige, S. H., Hjeltnes, A., Woodfin, V., \& Moltu, C. (2019). Becoming aware of inner self-critique and kinder toward self: A qualitative study of experiences of outcome after a brief selfcompassion intervention for university level students. Frontiers in Psychology, 10, 2728. https://doi.org/10.3389/fpsyg.2019.02728

Cali, B. E., Coleman, J. M., \& Campbell, C. (2013). Stranger danger? Women's self-protection intent and the continuing stigma of online dating. Cyberpsychology, Behavior, and Social Networking, 16(12), 853857. https://doi.org/10.1089/cyber.2012.0512

Campion, M., \& Glover, L. (2016). A qualitative exploration of responses to self-compassion in a non-clinical sample. Health \& social care in the community, 25(3), 1100-1108. https://doi.org/10.1111/hsc.12408

Čopková, R. (2019). Sebaoprávňovanie-efekt oprávňovania v kontexte self. [Self-licensing - licensing effect in the context of self]. Ceskoslovenska Psychologie,63(5),576-590. Retrieved from: https://www.proquest.com/docview/2319671520?accountid=17229\&forcedol=true

Ferguson, L. J., Kowalski, K. C., Mack, D. E., \& Sabiston, C. M. (2014). Exploring self-compassion and eudaimonic well-being in young women athletes. Journal of Sport \& Exercise Psychology, 36(2), 203-216. https://doi.org/10.1123/jsep.2013-0096

Germer, C. K. (2009). The mindful path to self-compassion: Freeing yourself from destructive thoughts and emotions. The Guilford Press.

Gilbert, P. (2010). An introduction to compassion focused therapy in cognitive behavior therapy. International Journal of Cognitive Therapy, 3(2), 97-112. https://doi.org/10.1521/ijct.2010.3.2.97 
Goldstein, W. M., \& Hogarth, R. M. (1997). Judgment and decision research: Some historical context. In W. M. Goldstein \& R. M. Hogarth (Eds.), Cambridge series on judgment and decision making. Research on judgment and decision making: Currents, connections, and controversies (pp. 3-65). Cambridge University Press.

Greenberg, L. S. (2002). Integrating an emotion-focused approach to treatment into psychotherapy integration. Journal of Psychotherapy integration, 12(2), 154. https://doi.apa.org/doi/10.1037/10530479.12 .2 .154

Greenberg, L. S. (2017). Emotion-Focused Therapy, Revised edition. American Psychological Association. https://content.apa.org/doi/10.1037/15971-001

Greenberg, L. S. (1979). Resolving splits: Use of the two chair technique. Psychotherapy: Theory, Research, and Practice, 16(3), 316-234. https://doi.apa.org/doi/10.1037/h0085895

Greenberg, L., Rice, L. \& Elliott, R. (1993). Facilitating emotional change: The moment by moment process. Guilford Press.

Halamová, J. (2015). Terapia zameraná na emócie. [Emotion-focused therapy]. Psychoterapeutické směry, 123.

Halamová, J. (2018). Sebasúcit a sebakritickost: Tvorba a meranie efektu intervencie. [Self-compassion and self-criticism - the development and measuring the effect of the intervention]. Vydavatel'stvo Univerzity Komenského.

Halamová, J., \& Kanovský, M. (2018). Sebasúcit a sebakritickost'. Psychometrická analýza meracích nástrojov. [Self-compassion and self-criticism - psychometric analysis of measures]. Univerzita Komenského v Bratislave.

Halamová, J., Baránková, M., Strnádelová, B., \& Koróniová, J. (2018a). Consensual qualitative research on free associations for compassion and self-compassion. Human Affairs, 28(3), 253-270. https://www.degruyter.com/document/doi/10.1515/humaff-2018-0021/html

Halamová, J., Kanovský, M., Varšová, K., \& Kupeli, N. (2018b). Randomised controlled trial of the new shortterm online emotion focused training for self-compassion and self-protection in a nonclinical sample. Current psychology, 1-11. https://doi.org/10.1007/s12144-018-9933-4

Halamová, J., Koróniová, J., \& Baránková, M. (2019). Differences in guided imagery between high and low self-critical participants: Consensual qualitative research analysis. The Qualitative Report, 24(12), 1186-1204. Retrieved from: https://doi.org/10.46743/2160-3715/2019.3891 
Hill, C. E., Thompson, B. J., \& Williams, E. N. (1997). A guide to conducting consensual qualitative research. The Counseling Psychologist, 25(4), 517-572. https://doi.org/10.1177\%2F0011000097254001

Koróniová, J., Halamová, J., \& Taňkošová, N. (2020). Level of self-criticism and changes in imagery among participants attending emotion focused training for self-compassion and self-protection. Československá psychologie, 64(5), 608-625.

Köhle, N., Drossaert, C., Jaran, J., Schreurs, K., Verdonck-de Leeuw, I. M., \& Bohlmeijer, E. T. (2017). Userexperiences with a web-based self-help intervention for partners of cancer patients based on acceptance and commitment therapy and self-compassion: a qualitative study. BMC Public Health, 17(1), 225. https://doi.org/10.1186/s12889-017-4121-2

Kramer, U., \& Pascual-Leone, A. (2016). The role of maladaptive anger in self-criticism: A quasi-experimental study on emotional processes. Counselling Psychology Quarterly, 29(3), 311-333. https://doi.org/10.1080/09515070.2015.1090395

Larrick, R. P. (1993). Motivational factors in decision theories: The role of self-protection. Psychological Bulletin, 113(3), 440. https://doi.apa.org/doi/10.1037/0033-2909.113.3.440

Marshall, S. L., Ciarrochi, J., Parker, P. D., \& Baljinder, K. S. (2020). Is Self-Compassion Selfish? The Development of Self-Compassion, Empathy, and Prosocial Behavior in Adolescence. Journal of Research on Adolescence, 30(2), 472-484. https://doi.org/10.1111/jora.12492

Murray, S. L., Derrick, J. L., Leder, S., \& Holmes, J. G. (2008). Balancing connectedness and self-protection goals in close relationships: A levels-of-processing perspective on risk regulation. Journal of Personality and Social Psychology, 94(3), 429. https://doi.apa.org/doi/10.1037/0022-3514.94.3.429

Neff, K. D. (2003a). Development and validation of a scale to measure self-compassion. Self and Identity, 2, 223-250. https://doi.org/10.1080/15298860309027

Neff, K. D. (2003b). Self-compassion: An alternative conceptualization of a healthy attitude toward oneself. Self and Identity, 2, 85-10. https://doi.org/10.1080/15298860309032

Neff, K. D. (2012). The science of self-compassion. In C. Germer \& R. Siegel (Eds.), Compassion and Wisdom in Psychotherapy (pp. 79-92). Guilford press.

Neff, K. D., \& Dahm, K. A. (2015). Self-compassion: what it is, what it does, and how it relates to mindfulness. In B. D. Ostafin, M. D. Robinson \& B. P. Meier (Eds.), Handbook of Mindfulness and Self-Regulation (pp. 121-137). https://doi.org/10.1007/978-1-4939-2263-5_10

Neff, K. D., Kirkpatrick, K. L., \& Rude, S. S. (2007a). Self-compassion and adaptive psychological functioning. Journal of Research in Personality, 41(1), 139-154. https://doi.org/10.1016/j.jp.2006.03.004 
Neff, K. D., Rude, S. S., \& Kirkpatrick, K. L. (2007b). An examination of self-compassion in relation to positive psychological functioning and personality traits. Journal of Research in Personality, 41(4), 908-916. https://doi.org/10.1016/j.jrp.2006.08.002

Neff, K. D., \& Vonk, R. (2009). Self-compassion versus global self-esteem: Two different ways of relating to oneself. Journal of Personality, 77, 23-50. https://doi.org/10.1111/j.1467-6494.2008.00537.x

Pascual-Leone, A., \& Greenberg, L, S., (2007). Emotional processing in experiential therapy: Why "The only way is through". Journal of Consulting and Clinical Psychology, 75(6), 875-887. https://doi.apa.org/doi/10.1037/0022-006X.75.6.875

Reed, K. L., \& Sanderson, S. N. (1999). Concepts of occupational therapy. Lippincott Williams \& Wilkins.

Rydé, K., Friedrichsen, M., \& Strang, P. (2007). Crying: A force to balance emotions among cancer patients in palliative home care. Palliative and Supportive Care, 5(1), 51-59.

https://doi.org/10.1017/S1478951507070071

Sedikides, C., \& Alicke, M. D. (2012). Self-Enhancement and Self-Protection Motives. In The Oxford Handbook of Human Motivation: Oxford University Press. [Link]

Scheier, M. F., \& Carver, C. S. (1993). On the power of positive thinking: The benefits of being optimistic. Current directions in psychological science, 2(1), 26-30. https://doi.org/10.1111\%2F14678721.ep10770572

Shahar, B., Carlin, E. R., Engle, D. E., Hegde, J., Szepsenwol, O., \& Arkowitz, H. (2012). A pilot investigation of emotion-focused two-chair dialogue intervention for self-criticism. Clinical Psychology \& Psychotherapy, 19(6), 496-507. https://doi.org/10.1002/cpp.762

Strauss, C., Lever Taylor, B., Gu, J., Kuyken, W., Baer, R., Jones, F., \& Cavanagh, K. (2016). What is compassion and how can we measure it? A review of definitions and measures. Clinical Psychology Review, 47, 15-27. https://doi.org/10.1016/j.cpr.2016.05.004

Sutherland, O., Peräkylä, A., \& Elliott, R. (2014). Conversation analysis of the two-chair self-soothing task in emotion-focused therapy. Psychotherapy Research, 24(6), 738-751. https://doi.org/10.1080/10503307.2014.885146

Timulak, L., \& Pascual-Leone, A. (2014). New developments for case conceptualization in emotion-focused therapy. Clinical Psychology \& Psychotherapy, 22(6), 619-636. https://doi.org/10.1002/cpp.1922

Whelton, W. J., \& Greenberg, L. S. (2005). Emotion in self-criticism. Personality and Individual Differences, 38(7), 1583-1595. https://doi.org/10.1016/j.paid.2004.09.024 
Woekel, E., \& Ebbeck, V. (2013) Transitional bodies: a qualitative investigation of postpartum body selfcompassion. Qualitative Research in Sport, Exercise and Health, 5(2), 245-266. https://doi.org/10.1080/2159676X.2013.766813

Yue, X., Anna, M. L. H., \& Hiranandani, N. A. (2017). How humor styles affect self-compassion and life satisfaction: A study in Hong Kong. Acta Psychopathologica 41(3). [Link]

\section{About the Authors}

Professor Júlia Halamová, PhD. is a psychologist and works at the Faculty of Social and Economic Sciences, Comenius University in Bratislava, Slovakia. She is on the list of psychotherapists of the Slovak Republic and she has her own private psychological and psychotherapeutic practice. She publishes in many prestigious journals such as Journal of Psychopathology and Behavioural Assessment, Perception, Applied Artificial Intelligence and Human Affairs. Her most important books include Self-compassion and self-criticism: Psychometric analysis of instruments (Comenius University in Bratislava, 2017), Psychological Sense of Community (Palacky University in Olomouc, 2014) Emotion Focused Therapy I. - textbook (Comenius University in Bratislava, 2013) and Emotion Focused Therapy II. - workbook (Comenius University in Bratislava, 2013). She focuses on psychology of emotions, community psychology, counseling psychology and psychotherapy. She has been selected as the regional coordinator for Slovakia within the European Community Psychology Association and also selected for the international coordinator of The Society for Community and Action Research (SCRA) Division 27 Americal Psychological Association. She is the member of International Society for Emotion Focused Therapy.

Bronislava Strnádelová, PhD. works at the Institute of Applied Psychology, Comenius University in Bratislava as an assistant professor at the Faculty of social and economic sciences. Bronislava does research in Eyetracking, Emotions and Applied Psychology. Her most recent research interests are in recognition of facial emotions and fixation patterns of self-critical/selfcompassionate individuals. She is a certified coder of facial emotions in Facial action coding system (FACS) and she has completed a basic training in Emotion focused therapy and Compassion focused therapy.

Viktória Vráblová, MA. is a postgraduate student at the Institute of Applied Psychology, Comenius University in Bratislava. 
Slávka Zlúkyová, MA. is a former student at the Institute of Applied Psychology, Comenius University in Bratislava.

Alžbeta Dvoranová, MA. is a former student at the Institute of Applied Psychology, Comenius University in Bratislava.

\section{Corresponding Author's Contact Address ${ }^{[T O P]}$}

Institute of Applied Psychology

Faculty of Social and Economic Sciences

Comenius University in Bratislava

Mlynské luhy 4

82105 Bratislava, Slovakia.

E-mail: julia.halamova@gmail.com 